\title{
Transcriptional activation and regulation of urokinase plasminogen activator inducted by LPS through MyD88 independent pathway in rat Sertoli cells
}

\author{
Yan Liu ${ }^{1,2 \dagger}$, Kai Zhao ${ }^{1 \dagger}$, Zhe Xiong ${ }^{3}$, Yuanxiao Yi ${ }^{1}$, Chengliang Xiong ${ }^{1}$, Donghui Huang ${ }^{*}$, \\ Hu Zhao ${ }^{*}$
}

${ }^{1}$ Institute of Reproduction Health, Tongji Medical College, Huazhong University of Science and Technology, Wuhan, China

${ }^{2}$ Puren Hospital Affiliated to Wuhan University of Science and Technology, Wuhan, China

${ }^{3}$ Department of Physiology, Medical School of Jianghan University, Wuhan, China

${ }^{4}$ Department of Human Anatomy, Tongji Medical College, Huazhong University of Science and Technology, Wuhan, China

\begin{abstract}
Introduction. Urokinase plasminogen activator (uPA) is a serine protease and it also demonstrates proinflammatory properties. We thus hypothesized that uPA is involved in immunity of Sertoli cells in the rat testis.

Materials and methods. The uPA gene(PLAU) promoter was cloned by RT-PCR and the transcriptional activation of core domain was screened by using Dual-Luciferase Reporter Assay System. The Sertoli cells were harvested from 20-day-old Sprague-Dawley male rats and total RNA was isolated. The uPA mRNA levels and MyD88 pathway were tested by qPCR.

Results. We successfully cloned the 1517-bp rat uPA gene and screened the core domain $(-455 /+40)$ in five different fragments of uPA promoter. The uPA expression and uPA promoter activity were upregulated in lipopolysaccharide (LPS)-stimulated Sertoli cells. Furthermore, the uPA expression was regulated through the MyD88-independent pathway by interdicting IRF3 and interferon $\beta$.

Conclusion. uPA expression is likely induced by LPS through the core promoter domain of uPA. This finding implied that uPA played a role in the immune function of Sertoli cells in rat testis, which might provide the development of new treatments for male infertility. (Folia Histochemica et Cytobiologica 2021, Vol. 59, No. 4, 236-244)
\end{abstract}

Key words: rat; Sertoli cells; urokinase plasminogen activator; lipopolysaccharide; uPA promoter

Correspondence address: $\mathrm{Hu} \mathrm{Zhao}$

Department of Human Anatomy, Tongji Medical College, Huazhong University of Science and Technology,

Wuhan 430030, Hubei Province, China

phone: +8613808674754

e-mail: zhaohu@hust.edu.cn

*Correspondence address: Donghui Huang

Institute of Reproduction Health, Tongji Medical College,

Huazhong University of Science and Technology,

Wuhan 430030, Hubei Province, China

phone: +8618872262607

e-mail: jhsyyjs@126.com; drjhsyyjs@163.com

$\dagger$ Yan Liu and Kai Zhao contributed equally to the work

\section{Introduction}

Plasmin is a serine protease that plays a crucial role in extracellular matrix (ECM) degradation under various physiological conditions [1]. Plasminogen is an inactive zymogen that can be activated by a limited proteolysis reaction catalyzed by two types of plasminogen activators (PA), namely, tissue-type PA (tPA) and urokinase-type PA (uPA) [2]. Circulating tPA is mainly involved in the activation of plasminogen during blood clotting in the degradation and dissolution of fibrin [3,4] while uPA is involved in

This article is available in open access under Creative Common Attribution-Non-Commercial-No Derivatives 4.0 International (CC BY-NC-ND 4.0) license, allowing to download articles and share them with others as long as they credit the authors and the publisher, but without permission to change them in any way or use them commercially. (C)Polish Society for Histochemistry and Cytochemistry 
various aspects of cellular migration and regulation [5]. Urokinase-type plasminogen activator was proved to be closely related to male reproduction, such as sperm progressive motility, acrosomal reaction, capacitation, chemotactic response, and fertilization [6-7]. In monkey, uPA is produced mainly in Sertoli cells [6], and the highest uPA expression is found at stages VII and VIII of the seminiferous epithelium cycle in rat [8]. However, uPA receptor was localized in germ cells of mature testis, but not in spermatogonia or late spermatids [9]. Our previous study showed that the expression of $u P A$ gene in rat was relatively high at postnatal Day 5 and Day 35, which indicated that uPA may be strongly linked to spermiation and spermatogenesis [10]. Downregulation of $u P A$ could decrease the fertility of male mice, which may be caused by a reduction in sperm motility [11].

Although the plasmin system was mainly known as the system responsible for vascular fibrinolysis, recent study also showed that it is critically important as a mediator of inflammation and the innate immune system, which impacts upon a diverse set of mechanisms underlying the pathologies of many diseases [12]. In a recent review it was described that plasmin was involved in many immunological processes by directly interacting with various cell types including monocytes, macrophages, dendritic cells and vascular wall cells (endothelial cells, smooth muscle cells) as well as soluble factors of the immune system and components of the ECM [13]. Furthermore, uPA could become a new target for immunocontraception in developing male contraceptives [14]. Thus, the regulation mechanisms of uPA in Sertoli cells require further studies.

Eukaryotic gene expression regulation can be divided into two major categories according to their nature: the first category is the instantaneous or reversible gene regulation, the equivalent of prokaryotic cells in response to different environmental conditions; the other is developmental or irreversible gene regulation, is the essence of eukaryotic gene regulation, which determines the whole process of growth, differentiation and development of eukaryotic cells [15]. Transcription regulation is the most important control point in the regulation of eukaryotic gene expression, while a promoter is a region of DNA that initiates transcription of a particular gene [16]. Therefore, studying the functional motif of promoters is of great significance for the research of regulation mechanisms of gene expression. Although uPA plays an important role in male reproduction, the transcription regulation mechanism of uPA remains unclear.

To study the transcription regulation mechanism of $u P A$ gene expression in rat Sertoli cell, we carried out the cloning and analysis of the promoter region of the rat uPA gene, and subcloned the Plau core promoter nucleotide sequence containing approximately 1.6-kb 5'-flanking region [17]. In addition, uPA has been shown to demonstrate potent proinflammatory properties $[18,19]$. The domains responsible in the uPA molecule for proinflammatory activity involved in neutrophil activation are distinct from those responsible for fibrinolytic or chemotactic properties [20]. Furthermore, uPA induction by inflammatory stimuli, such as IL-1, TNF, and lipopolysaccharide (LPS), has been reported in a number of human cells [21]. The activation of TLR signaling pathways plays an essential role in the detection of invading pathogens. After LPS stimulation, the response may be mediated by MyD88-dependent or MyD88-independent pathways, which leads to the activation of MAP kinases and NF- $\kappa \mathrm{B}$ [22].

This study examined the trans-acting factors involved in LPS regulation of $u P A$ gene expression and the related pathway to explore the role of uPA in the male reproductive system.

\section{Materials and methods}

Animals. Twelve male Sprague-Dawley rats (20-day-old) were purchased from the Animal Center of Tongji Medical College, Huazhong University of Science and Technology (Wuhan, China). The rats were reared under a $12 \mathrm{~h}$ light/ /dark cycle and provided with free access to food and water. All experiments were conducted in accordance with formal approval from the Animal Ethics Committee of Tongji Medical College, Huazhong University of Science and Technology (Approval No. 2012-0917). In addition, the animals were handled in accordance with the Guide for Laboratory Animals of the National Institutes of Health.

Isolation and culture of rat Sertoli cells. Sertoli cells were harvested from 20-day-old Sprague-Dawley male rats. The primary Sertoli cell culture was prepared as described previously [23]. Testis fragments were subjected to sequential enzymatic digestion using $0.25 \%$ trypsin (Gibco, Grand Island, NY, USA), $1 \mathrm{mg} / \mathrm{mL}$ hyaluronidase (SigmaAldrich, Louis, St. MO, USA), and $0.1 \%$ collagenase I (SigmaAldrich) at $37^{\circ} \mathrm{C}$ for $15-30,30$, and $60 \mathrm{~min}$, respectively. The Sertoli cells were allowed to settle between enzymatic treatments and washes through sediment gravity flow. The final cell suspension was resuspended in DMEM/F12 (Gibco) supplemented with $10 \%$ fetal calf serum (FCS), $10 \mu \mathrm{g} / \mathrm{mL}$ insulin, $5 \mu \mathrm{g} / \mathrm{mL}$ transferrin, and $5 \mathrm{~g} / \mathrm{L} \mathrm{EGF}$ (SigmaAldrich) in a final cell concentration of $1 \times 10^{6}$ viable cells $/ \mathrm{mL}$. The Sertoli cell suspension $(2 \mathrm{~mL})$ was subsequently seeded in each well of six-well plates and then cultured at $34^{\circ} \mathrm{C}$ in a highly humidified incubator with 
$5 \% \mathrm{CO}_{2}$. After $48 \mathrm{~h}$, the cells were treated with a hypotonic solution (20 mM Tris-HCl, $\mathrm{pH} 7.4$ ) to remove the contaminating germ cells.

Immunofluorescence. The cultured rat Sertoli cells were fixed in $4 \%$ paraformaldehyde for $15 \mathrm{~min}$. The cells was then processed through blocking steps using $0.25 \%$ Triton-X, anti-uPA antibody incubation at 1:1000 (Abcam, Cambridge, MA, USA) for 12 hours at $4^{\circ} \mathrm{C}$, rinse/blocking steps, followed by incubation with FITC fluorophore-conjugated secondary antibodies (Thermo Fisher Scientific, Waltham, MA, USA), and DAPI (Invitrogen, Carlsbad, CA, USA) nuclear staining. Cell climbing piece were imaged on an Olympus IX70 (Olympus, Tokyo, Japan) fluorescence microscope.

Renilla luciferase reporter assays. In the transient transfection experiments, the Sertoli cells were seeded into six-well plates at a density of $2 \times 10^{6}$ cells per well. The cells were transfected with $350 \mathrm{ng}$ of plasmid, which was prepared using endotoxin-free plasmid isolation kits (Qiagen, Valencia, CA, USA) containing the uPA promoter. The thymidine kinase Renilla luciferase reporter vector (PGL3-Enhancer, Promega, Madison, WI, USA, 40 ng/well) was co-transfected to normalize data and ensure transfection efficiency. Plasmids were transfected using Lipofectamine 2000 (Invitrogen). After 24 h, total cell lysates were prepared and analyzed for luciferase activity by using Dual-Luciferase Reporter Assay System Kit (Promega) according to the manufacturer's protocol.

LPS-induced uPA expression in Sertoli cells. The Sertoli cells were seeded into six-well plates at a density of $2 \times$ $10^{6}$ cells per well. The cells were transfected with $380 \mathrm{ng}$ of PGL3-499 plasmid containing the uPA promoter or with PGL3-control (Promega) luciferase reporter gene plasmid containing the SV40 promoter by using Lipofectamine 2000. On the following day, the cells were incubated with LPS $(20 \mu \mathrm{g} / \mathrm{mL})$ (SigmaAldrich) for $0,12,24$, or $48 \mathrm{~h}$. The LPS concentration $(20 \mu \mathrm{g} / \mathrm{ml})$ was selected according to the data presented by Cudicini et al. [23] and Wendy et al. [24]. Cell lysates were prepared and analyzed for luciferase activity by using the Dual-Luciferase Reporter Assay System Kit (Promega) according to the manufacturer's protocol. Data are expressed as the means of relative stimulation $\pm \mathrm{SD}$.

Real-time PCR analysis. Real-time PCR analysis was performed using Power SYBR ${ }^{\circledR}$ Green PCR Mix Kit on ABI PRISM 7300 real-time cycler (Applied Biosystems, Foster City, CA, USA). Total RNA was extracted from $1 \times 10^{6}$ Sertoli cells by using TRIZOL reagent (Invitrogen) according to the manufacturer's instruction. cDNA synthesis was performed with the purified RNA by using the SuperScript III First-strand Synthesis System (Invitrogen). The reaction system of $20 \mu \mathrm{L}$ of reaction mixture, including $2 \mu \mathrm{L}$ of cDNA, $1 \mu \mathrm{L}$ of the forward primers, and $1 \mu \mathrm{L}$ of reverse primers, and $10 \mu \mathrm{L}$ of SYBR Green PCR MasterMix (Takara, Tokyo, Japan). The steps were as follows: (1) $95^{\circ} \mathrm{C}$ for $30 \mathrm{~s}$ and (2) amplification over 40 cycles at $95^{\circ} \mathrm{C}$ for $5 \mathrm{~s}$ and $58^{\circ} \mathrm{C}$ for $30 \mathrm{~s}$. All samples were normalized against $\beta$-actin by using the comparative CT method $(\Delta \Delta \mathrm{CT})$. Table 1 shows the primer sequences. In addition, mRNA expression was determined using the $2^{-\Delta \Delta \mathrm{Cq}}$ method.

The intervening experiment in Sertoli cells. Sertoli cells were treated in vitro by blank control, LPS $(20 \mu \mathrm{g} / \mathrm{mL}$, SigmaAldrich), anti-IRF3 (10 nM, Amersco, Solon, OH, USA), LPS + anti-IRF3, LPS + IFN- $\beta$ (20 nM, SigmaAldrich) and IFN- $\beta$ groups, and the induction time was $0,12,24$ or 48 hours respectively. The levels of uPA mRNA and protein were detected by Real-time PCR and Western-blot with $\beta$-Actin as internal reference.

Western blot analysis. Sertoli cells were washed with icecold buffered saline (PBS) and lysed using lysis buffer (10\% glycine, $150 \mathrm{mM} \mathrm{NaCl}, 1.0 \%$ NP-40, $10 \mathrm{mM}$ EDTA, $20 \mathrm{mM}$ NaF, $1 \mathrm{mM}$ vandate, $1 \mathrm{mM}$ benzamidine) on ice for $30 \mathrm{~min}$. Protein concentration in the lysates was determined using BCA Kit (Life Technologies, Carlsbad, CA, USA). The lysates were boiled for $4 \mathrm{~min}$ and then subjected to electrophoretic separation on 4-20\% SDS-polyacrylamide gel (Life Technologies, USA). The proteins were transferred onto Immobilon-P membrane (Millipore, Darmstadt, Germany). The blots were incubated in a blocking buffer (PBS containing $0.05 \%$ Tween and $5 \%$ nonfat dry milk) for $30 \mathrm{~min}$ and probed with primary antibody, anti-uPA (Abcam, Cambridge, MA, USA), or anti- $\beta$-actin (Santa Cruz Biotechnology, Santa Cruz, CA, USA). After three 10-min washes with PBS containing $0.05 \%$ Tween 20 , the membranes were incubated for $1 \mathrm{~h}$ with goat anti-rabbit immunoglobulin G (1:5000, Thermo Fisher Scientific) in blocking buffer. The immunoreactive proteins were then visualized using Supersignal West Pico Chemiluminescence Kit (Thermo Fisher Scientific). Band density was quantified using the software Gel-Pro Analyzer 4.

Statistical analysis. All experiments were performed in triplicate, and numerical data are presented as means \pm SD. The statistical differences between groups were tested by one-way ANOVA. All data were analyzed using SPSS version 17.0 (SPSS Inc., Chicago, IL, USA). Values were significantly different if two-tailed $P$ value was $<0.05$.

\section{Results}

\section{Identification of core promoter of the rat uPA gene by luciferase assay}

Five fragments of the uPA promoter region, namely, $211(-167 /+40), 499(-455 /+40), 802(-758 /+40), 1220$ $(-1156 /+40)$, and 1588 bp $(-1544 /+40)$, were amplified from different regions and verified by electropho- 
Table 1. The list of primers in this study

\begin{tabular}{|c|c|c|c|}
\hline Target & Primer & Sequences & Region(bp) \\
\hline \multicolumn{4}{|c|}{ Primers for gene clone } \\
\hline \multirow[t]{2}{*}{ uPA } & Sense & 5'-AGGCTAGGCTCACCACCAAAG-3' & \\
\hline & Antisense & 5'-CGCAAGGACTGGATTGATGAC-3' & \\
\hline 1588bp & Sense & 5'-ctcgagATGATTGGCAGCAGGAGAGAC-3' & $-1544 /+40$ \\
\hline $1220 \mathrm{bp}$ & Sense & 5'-ctcgagATCCGATGCCCTCTTCTGGT-3' & $-1156 /+40$ \\
\hline $802 \mathrm{bp}$ & Sense & 5'-ctcgagTGGATTGAAGGGTATGCCATT-3' & $-758 /+40$ \\
\hline 499bp & Sense & 5'-ctcgagCAGCATTTGACATGTGGGAAC-3' & $-455 /+40$ \\
\hline $211 b p$ & Sense & 5'-ctcgagTGGAAATCCCATGACTTCGTC-3' & $-167 /-40$ \\
\hline common & Antisense & 5'-aagcttAGACACGCAAGGACTGGATTG-3' & \\
\hline \multicolumn{4}{|c|}{ Primers for real-time PCR } \\
\hline \multirow[t]{2}{*}{ IL-1 } & Sense & 5'-GGACAGAACATAAGCCAACA-3' & \\
\hline & Antisense & 5'-TTAGGAATAGTGCAGCCATC-3' & \\
\hline \multirow[t]{2}{*}{ IL-6 } & Sense & 5'-GTATGAACAGCGATGATGC-3' & \\
\hline & Antisense & 5'-AAACGGAACTCCAGAAGACC-3' & \\
\hline \multirow[t]{2}{*}{ uPA } & Sense & 5'-TGGTGGGAGCCTCATCAGT-3' & \\
\hline & Antisense & 5'-CCCGTGCTGGTACGTATCTT-3' & \\
\hline \multirow[t]{2}{*}{$\beta$-actin ${ }^{\mathrm{a}}$} & Sense & 5'CACCCGGAGTACAACCTTC-3' & for uPA \\
\hline & Antisense & 5'-CССАТАСССАССАТСАCACC-3' & \\
\hline \multirow[t]{2}{*}{$\beta$-actin ${ }^{\mathrm{b}}$} & Sense & 5'-GTCAGGTCATCACTATCGGCAAT-3' & for IL-1,IL-6 \\
\hline & Antisense & 5'AGAGGTCTTTACGGATGTCAACGT-3' & \\
\hline
\end{tabular}

a $\beta$-actin is the internal reference of $\mathrm{uPA}$; ${ }^{\mathrm{b}} \beta$-actin is the internal reference of IL-1 and IL-6.

resis (Fig. 1A). These fragments were independently constructed into the PGL3-enhancer flu reporter vector. The plasmids were successfully identified via double digestion (Fig. 1B) and named as PGL3-211, PGL3-499, PGL3-802, PGL3-1220, and PGL3-1588, respectively. This series of fragments demonstrated significantly different promoter activities when their recombinant vectors were transfected into Sertoli cells. Among them, PGL3-499 showed the highest promoter activity (Fig. 1C).

\section{Upregulation of uPA expression and $\mathrm{UPA}$ promoter activity in LPS-stimulated Sertoli cells}

To explore the potential immunologic function of uPA in Sertoli cells, we assessed uPA expression after adding LPS. The results showed that LPS-stimulated Sertoli cells in which the uPA protein was labeled with red fluorescence antibody by using immunofluorescence technology, displayed a significantly upregulated uPA expression after $12 \mathrm{~h}$ of incubation (Fig. 2A). When LPS was added into the cultured Sertoli cells, the proportion of uPA-positive cells significantly increased, as revealed by statistical analysis, and then peaked after $12 \mathrm{~h}$ (Fig. 2B, $62.3 \pm 4.5 \%$ vs. $23.6 \pm 2.1 \%, P<0.05$ ). To further investigate the cause of the upregulated uPA expression, we detected the promoter activity of uPA, especially the screened region, through Renilla luciferase reporter assays. The result showed that the promoter activity of PGL3-control containing the SV40 promoter was not obviously affected by LPS after $48 \mathrm{~h}$. However, in the core promoter of UPA, the plasmid PGL3-499 was interfered by addition of LPS $(20 \mu \mathrm{g} / \mathrm{mL})$ to Sertoli cell cultures (Fig. 2C) after $12 \mathrm{~h}$; moreover, uPA promoter activity was significantly upregulated and peaked at $24 \mathrm{~h}$ (Fig. 2C, $P<0.05$ ).

\section{Downregulation of IL-1 and IL-6 by anti-IRF3 in LPS-stimulated Sertoli cells}

Numerous studies confirmed that LPS stimulates IL-1 and IL-6 mRNA. The present results showed that IL-1 and IL-6 mRNA expression levels in Sertoli cells were both significantly upregulated $12 \mathrm{~h}$ after adding LPS (Fig. 3). TLR4 signaling occurs along into two pathways, the MyD88-dependent and MyD88-independent. In the latter, the transcription factor IRF3 is crucial for the activation of the TIR-containing adaptor protein. To explore whether the process involves the MyD88-independent NF- $\kappa \mathrm{B} /$ /JNK pathway, we added $10 \mathrm{nM}$ anti-IRF3 to Sertoli 


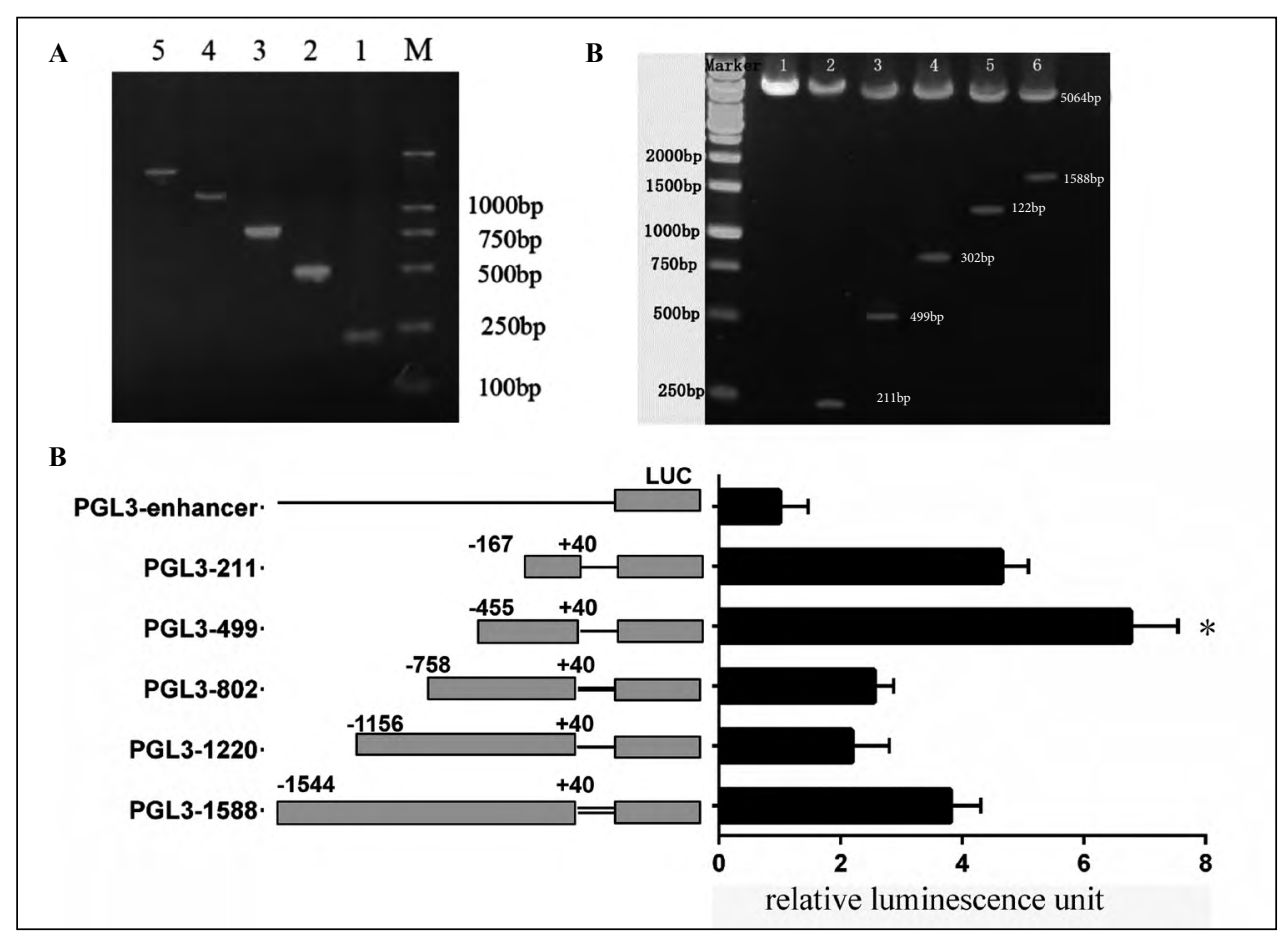

Figure 1. Core promoter of rat urokinase plasminogen activator (uPA) gene was identified by luciferases assay. A. Different length of the uPA promoter regions (211bp, 499bp, 802bp, 1220bp and 1588bp) were amplified and verified by electrophoresis. Marker: DL2000 (TaKaRa, Japan). B. Plasmid was verified by enzyme digest. Marker: 1KB DNA marker (Fermtas, USA), PGL3-enhancer; PGL3-211; PGL3-499; PGL3-802; PGL3-1220; PGL3-1588. C. Renilla luciferases (RL) density was examined in different region of promoter transfected into Sertoli cell. PGL3-499 showed the highest promoter activity compared with other groups. * $\mathrm{P}<0.05$ compared with PGL3-enhancer group.

cells cultured with or without LPS. The results showed that the IL-1 and IL- 6 mRNA levels of the anti-IRF3 group were unchanged compared with those in the blank group but were significantly downregulated compared with those in the LPS+anti-IRF3 group (Fig. 3). This finding confirmed that IRF3 is a key factor in the signaling pathway of IL-1 and IL-6 in Sertoli cells stimulated with LPS.

\section{uPA pathway in LPS-stimulated Sertoli cells}

To further study the candidate pathway of uPA regulation, we tested the $u P A$ mRNA expression in different experimental groups. The $u P A$ mRNA level was significantly lower in the blank group than those in the LPS, interferon $\beta$ (IFN- $\beta$ ), LPS +IFN- $\beta$, and LPS + anti-IRF3 groups $(P<0.01, P<0.05$, $P<0.001$, and $P=0.028$, respectively) (Fig. 4A). In addition, $u P A$ mRNA expression was significantly higher in the LPS+anti-IRF3 group than that in the anti-IRF3 group $(P=0.001)$. The $u P A$ mRNA expression was also significantly higher in the LPS + IFN- $\beta$ group than that in the IFN- $\beta$ group $(P<0.01)$. Furthermore, the uPA protein was higher in the LPS + IFN $-\beta$ group than those in the other groups (Fig. 4B). Moreover, uPA protein expression in the LPS group stimulated for $12 \mathrm{~h}$ was significantly different from those in groups stimulated for $24 \mathrm{~h}$ and $48 \mathrm{~h}$, which is consistent with the previous immunocytochemical results. The protein expression of uPA in the IFN- $\beta$ group was also not significantly different from that in the LPS+anti-IRF3 group. These results suggested that LPS induced Sertoli cell activation through the IRF3-independent mechanism.

\section{Discussion}

In this study, we identified the rat $u P A$ gene and examined its promoter and activity. Sequence analysis revealed that the $u P A$ genomic gene is composed of the 5'-flanking region (approximately $1.6 \mathrm{~kb}$ ) containing a typical GC/TATA box. In addition, the mammalian $u P A$ promoter contains enhancer elements, such as AP-1 and SP-1; the binding of these enhancers to the corresponding transcription factors will enhance gene transcription $[25,26]$. In the present study, we demonstrated a protein-binding site overlapping the GC-box element (GGGCGG) between -61 and -56 . We examined the $u P A$ promoter activity by using Dual-Luciferase assay techniques, which are useful for rapid and accurate determination of the activity of a given promoter in a cell line [27]. The results showed that all of the fragments displayed a promoter activ- 


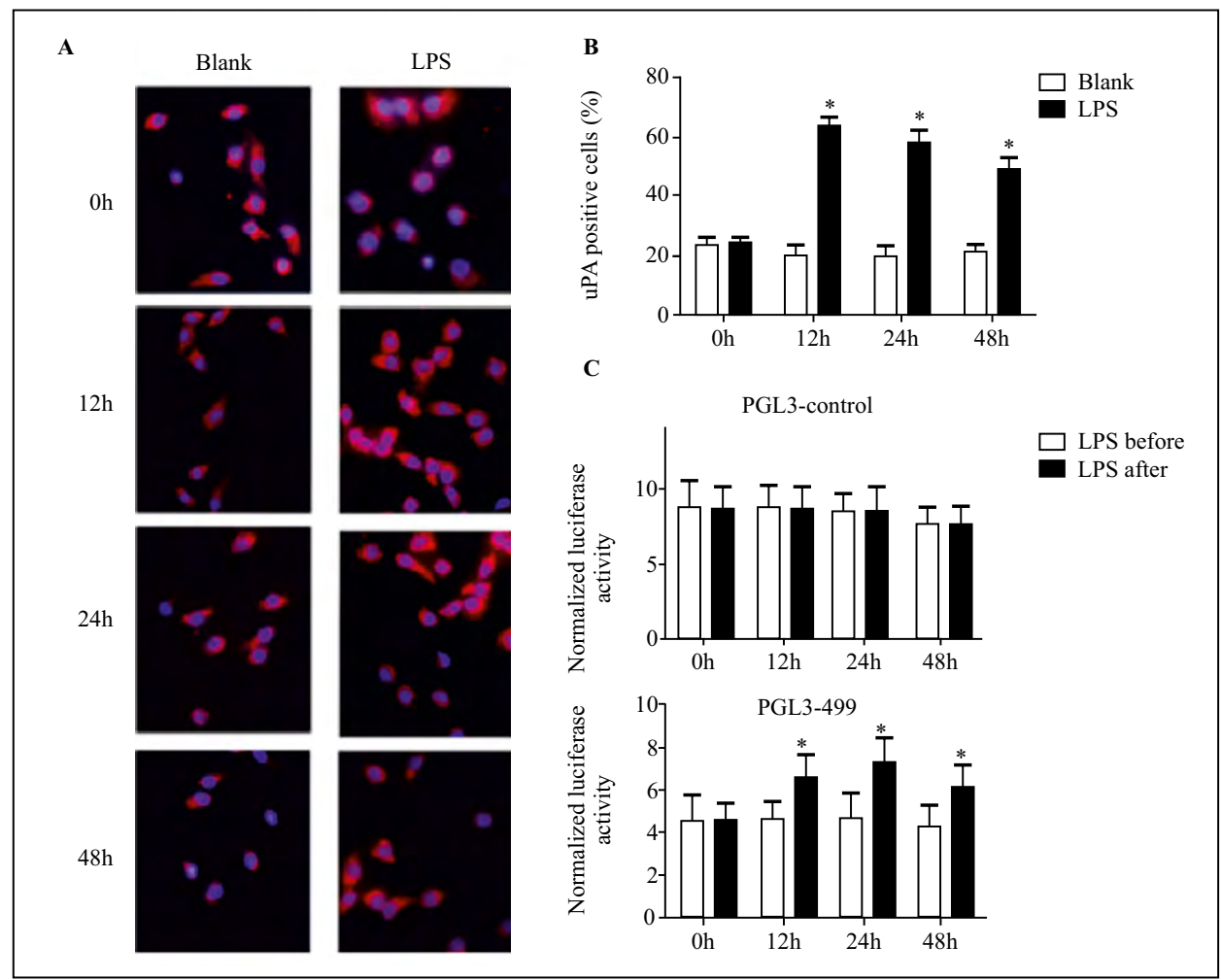

Figure 2. Urokinase plasminogen activator (uPA) expression in rat Sertoli cells stimulated with LPS (20 $\mu \mathrm{g} / \mathrm{ml})$. A. Representative microphotographs of the expression of uPA in Sertoli cells in a time-dependent manner with or without LPS-stimulation visualized by immunofluorescence. uPA protein was labelled with red fluorescence antibody, and cell nucleus was stained with DAPI as described in Methods. B. Proportion of uPA-positive cells in Sertoli cell in blank or LPS group. The uPA expression was significantly upregulated compared with blank group after $12 \mathrm{~h}$. C. Renilla luciferases activity after incubation with LPS $(20 \mu \mathrm{g} / \mathrm{mL})$ with PGL3-enhancer or PGL3-499 in Sertoli cells as incubated for the indicated time point. ${ }^{*} P<0.05$ compared with blank group.

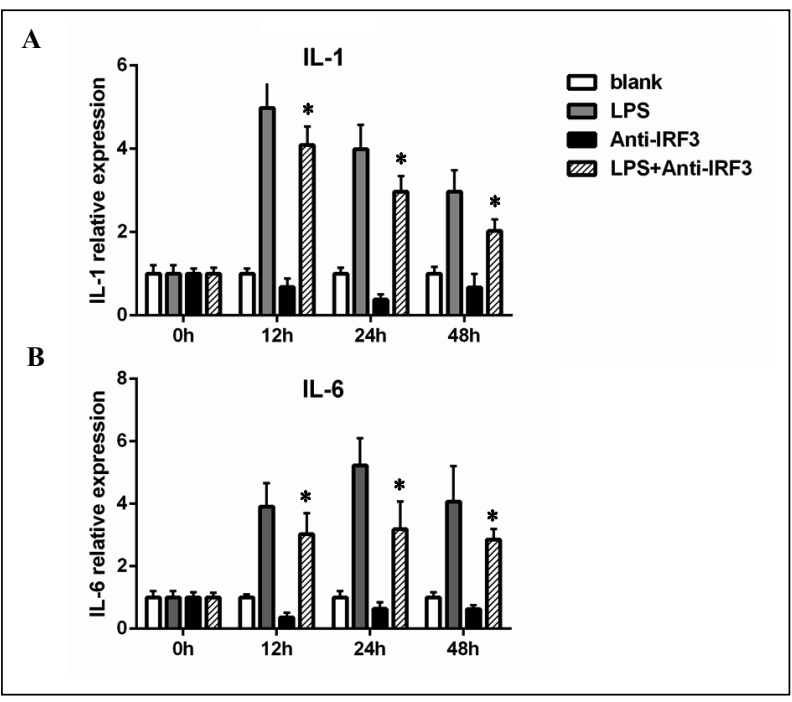

Figure 3. The IL-1 and IL-6 expression in rat Sertoli cells in different groups at various times. Sertoli cells were incubated with or without LPS and anti-IRF3 (10 nM), the IL-1 (A) and IL-6 (B) mRNA levels were determined by real-time PCR, and normalized to $\beta$-actin mRNA. The IL- 1 and IL-6 mRNA levels in the LPS + anti-IRF3 group were significantly downregulated compared with those in the LPS group. ${ }^{*} P<$ 0.05 compared with LPS group. ity when the recombinant vectors were transfected into Sertoli cells [28]. PGL3-499 showed the highest promoter activity (Fig. 1C), indicating that an important element functioning in negative regulation was deleted in the pGL3-499 plasmid. PGL3-499, which has a 499-bp core promoter containing GC/TATA box upstream the translation initiation codon, showed a significantly high promoter activity. The data also suggested that the regulatory promoters or enhancers and other c/s-elements present from -1156 to -1544 are necessary to maintain uPA-specific expression.

Sertoli cells play an important role in spermatogenesis by creating microenvironment that protects germ cells in the wall of seminiferous tubules. Sertoli cells are part of the blood-testis barrier (BTB), which separates the seminiferous epithelium into two distinct compartments. Therefore, Sertoli cells mechanically segregate germ cell autoantigens by means of the BTB and create an effective immune-privileged environment that protects germ cells from invading pathogens [28]. Sertoli cells can phagocytose the apoptotic spermatogenic cells and apoptotic bodies to prevent the autoimmune reaction from the latent antigen of the spermatogenic cell. Sertoli cells also 


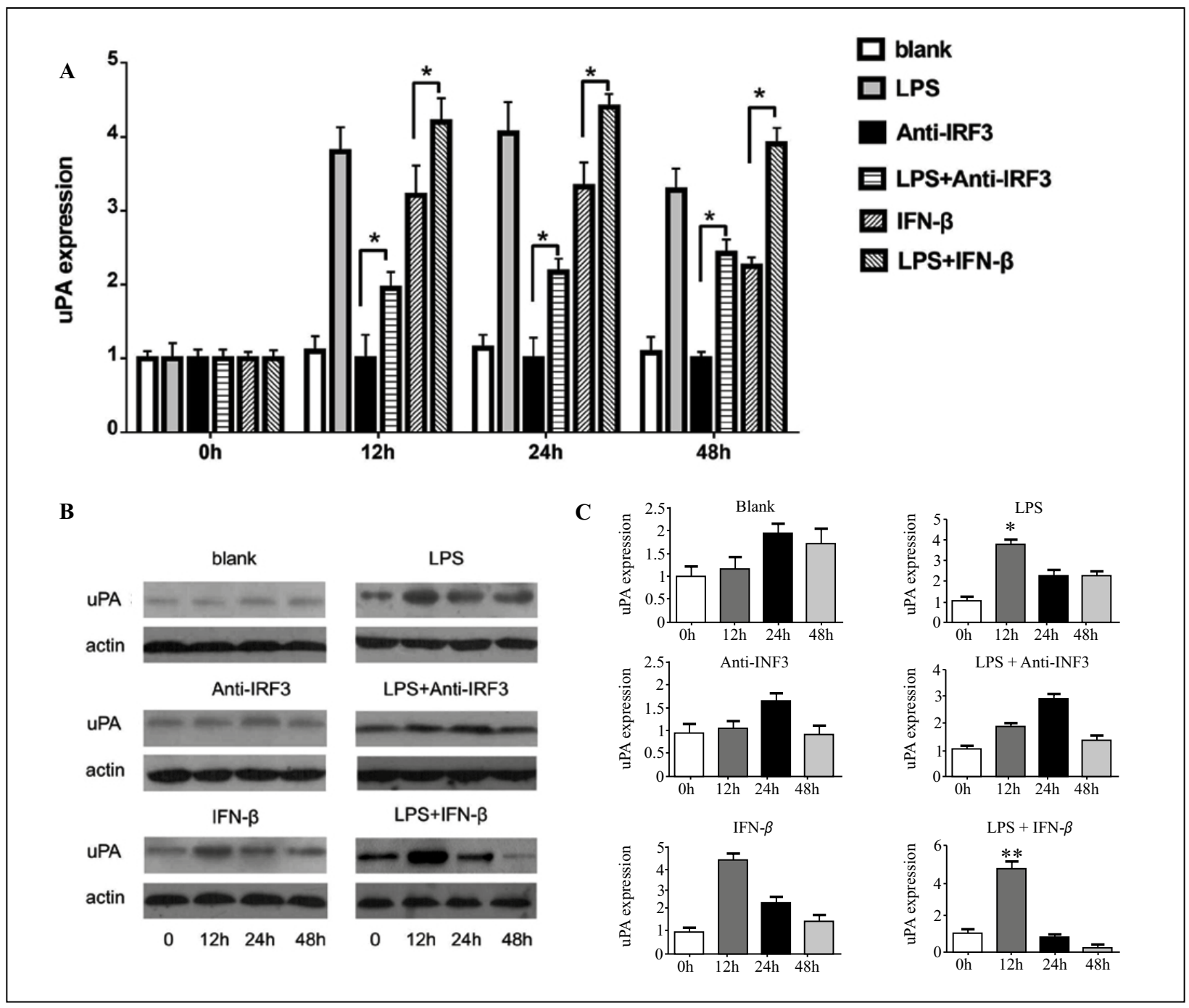

Figure 4. Urokinase plasminogen activator (uPA) mRNA and protein expression in rat Sertoli cells in the different experimental groups at various time points. A. uPA mRNA level of a different group at various time points was assessed by real-time PCR. uPA mRNA level was significantly higher in the LPS + anti-IRF3 group than that in the anti-IRF3 group (P $<0.05)$. B. uPA protein expression of different groups at various time points was assessed by Western blotting. C. Statistical analysis of the mean light density of picture. uPA protein expression in the LPS group stimulated for $12 \mathrm{~h}$ was significantly upregulated compared with those in cells stimulated for 24 or $48 \mathrm{~h}$. uPA protein levels were also higher in the LPS + IFN- $\beta$ group than those in the other groups ${ }^{*} P<0.05,{ }^{*} P<0.01$ compared with the LPS group.

contain an immune-privileged site, where both alloand autoantigens can be tolerated [29]. As a result, Sertoli cells have been identified as key players for conferring this immune privilege [30].

LPS are found in the outer membrane of Gram-negative bacteria, and elicit strong immune responses. When LPS particles released from the bacterial wall invade the tissues, they cause the release of inflammatory mediators through the TLR signaling pathways $[31,32]$. In this study, we isolated Sertoli cells from 20-d-old Sprague-Dawley male rats because Sertoli cells become mature and are not easily contaminated by germ cells at this time. The present study clearly demonstrated that uPA gene expression was upregu- lated by LPS in cultured rat Sertoli cells, which indicated that LPS may stimulates the degradation of the ECM by increasing of UPA expression and interfere with the immune defense mechanism of Sertoli cells.

Several lines of evidence have shown that LPS can activate the transcriptional factors NF- $\kappa \mathrm{B}$ and cAMP-response element binding protein (CREBP) $[33,34]$. LPS can induce systemic inflammatory response via MyD88-dependent or MyD88 independent pathway [35]. In MyD88-dependent pathway, MyD88 is recruited to the Toll-like receptor 4 (TLR4) through interaction with the TIR domain of TLR4 whereas MyD88-deficient cells failed to produce any pro-inflammatory cytokines such as interleukin-1 $\beta$ (IL-1 $\beta)$, 
IL-6, and TNF in response to LPS [36]. The cytokines IL- $1 \alpha$ and IL- 6 were found in the testis at high levels, which were closely related to immune defense response of Sertoli cells $[37,38]$. Interferon regulatory factor 3 (IRF-3) plays a key role in MyD88-independent signaling pathway [39]. We showed that LPS stimulated the expression of IL-1 and IL-6 in Sertoli cells, while IRF3 antibody(anti-IRF3) antagonized this response, indicating that LPS induced the immune response of Sertoli cells through MyD88-independent pathway. Anti-IRF3 can significantly decrease the LPS-induced increase of uPA expression. Thus, our experiments demonstrated that LPS could increase the expression of uPA through MyD88-independent pathway.

In summary, we found that uPA gene contains the 5'-flanking region (approximately $1.6 \mathrm{~kb}$ ) with a typical GC/TATA box. PGL3-499, which has a 499bp core promoter contains GC/TATA box upstream the translation initiation codon. uPA expression in Sertoli cells is regulated through MyD88-independent pathway induced by LPS stimulation. This finding implied that uPA plays a role in the immune function of Sertoli cells in rat testis, and may provide a new target for the treatment of male immune-related infertility.

\section{Funding}

This work was supported by the National Natural Science Foundation of China (NO: 81771575, 81701539) and Wuhan Municipal Health scientific research project (EX20E16). The authors declare that there is no conflict of interest that would prejudice the impartiality of this work.

\section{Availability of data and materials}

The datasets used and/or analyzed during the current study are available from the corresponding author on reasonable request.

\section{Authors' contributions}

YL and $\mathrm{KZ}$ conducted laboratory studies, wrote the article, and performed all necessary literature searches and data compilation. ZX, CL X, YY X performed the necessary literature searches and data compilation. $\mathrm{HZ}$ and $\mathrm{DH} \mathrm{H}$ designed the review, reviewed, and approved the submitted manuscript. All authors have read and approved the final manuscript.

\section{Ethics approval and consent to participate}

All experiments were conducted in accordance with formal approval from the Animal Ethics Committee of Tongji Medical College, Huazhong University of
Science and Technology (Approval No. 2012-0917). In addition, the animals were handled in accordance with the Guide for Laboratory Animals of the National Institutes of Health.

\section{Conflicts of interest}

The authors declare that they have no conflicts of interest to report regarding the present study.

\section{References}

1. Foley JH. Plasmin(ogen) at the Nexus of Fibrinolysis, Inflammation, and Complement. Semin Thromb Hemost. 2017; 43(2): 135-142, doi: 10.1055/s-0036-1592302, indexed in Pubmed: 28052305.

2. Draxler DF, Sashindranath M, Medcalf RL. Plasmin: A Modulator of Immune Function. Semin Thromb Hemost. 2017; 43(2): 143-153, doi: 10.1055/s-0036-1586227, indexed in Pubmed: 27677178.

3. Coutts SB, Dubuc V, Mandzia J, et al. TEMPO-1 Investigators. Tenecteplase-tissue-type plasminogen activator evaluation for minor ischemic stroke with proven occlusion. Stroke. 2015; 46(3): 769-774, doi: 10.1161/STROKEAHA.114.008504, indexed in Pubmed: 25677596.

4. Wang C, Huang R, Li C, et al. Vepoloxamer Enhances Fibrinolysis of tPA (Tissue-Type Plasminogen Activator) on Acute Ischemic Stroke. Stroke. 2019; 50(12): 3600-3608, doi: 10.1161/ STROKEAHA.119.026049, indexed in Pubmed: 31587657.

5. Mekkawy AH, Pourgholami MH, Morris DL. Involvement of urokinase-type plasminogen activator system in cancer: an overview. Med Res Rev. 2014; 34(5): 918-956, doi: 10.1002/ med.21308, indexed in Pubmed: 24549574.

6. Liu YX. Involvement of plasminogen activator and plasminogen activator inhibitor type 1 in spermatogenesis, sperm capacitation, and fertilization. Semin Thromb Hemost. 2007; 33(1): 29-40, doi: 10.1055/s-2006-958459, indexed in Pubmed: 17253187.

7. Martinez-Soto JC, Landeras J, Mollá M, et al. Total urokinase-type plasminogen activator (uPA) levels in seminal plasma are associated with positive assisted reproductive technology outcomes. J Assist Reprod Genet. 2018; 35(6): 1091-1101, doi: 10.1007/s10815-018-1164-y, indexed in Pubmed: 29572694.

8. Penttilä TL, Kaipia A, Toppari J, et al. Localization of urokinase- and tissue-type plasminogen activator mRNAs in rat testes. Mol Cell Endocrinol. 1994; 105(1): 55-64, doi: 10.1016/0303-7207(94)90035-3, indexed in Pubmed: 7821718.

9. Zhang T, Zhou HM, Liu YX. Expression of plasminogen activator and inhibitor, urokinase receptor and inhibin subunits in rhesus monkey testes. Mol Hum Reprod. 1997; 3(3): 223-231, doi: 10.1093/molehr/3.3.223, indexed in Pubmed: 9237248.

10. Huang DH, Zhao Hu, Tian YH, et al. Gene expression changes of urokinase plasminogen activator and urokinase receptor in rat testes at postnatal stages. Asian J Androl. 2007; 9(5): 679-683, doi: 10.1111/j.1745-7262.2007.00272.x, indexed in Pubmed: 17712486.

11. Zhao K, Liu Y, Xiong Z, et al. Tissue-specific inhibition of urokinase-type plasminogen activator expression in the testes of mice by inducible lentiviral RNA interference causes male infertility. Reprod Fertil Dev. 2017; 29(11): 2149-2156, doi: 10.1071/RD16477, indexed in Pubmed: 28298247.

12. Foley JH. Plasmin(ogen) at the Nexus of Fibrinolysis, Inflammation, and Complement. Semin Thromb Hemost. 
2017; 43(2): 135-142, doi: 10.1055/s-0036-1592302, indexed in Pubmed: 28052305.

13. Draxler DF, Sashindranath M, Medcalf RL. Plasmin: A Modulator of Immune Function. Semin Thromb Hemost. 2017; 43(2): 143-153, doi: 10.1055/s-0036-1586227, indexed in Pubmed: 27677178

14. Ding X, Li H, Li Y, et al. Two B-cell epitope vaccines based on uPA effectively inhibit fertility in male mice. Vaccine. 2018; 36(19): 2612-2618, doi: 10.1016/j.vaccine.2018.03.071, indexed in Pubmed: 29631885.

15. Li X, Egervari G, Wang Y, et al. Regulation of chromatin and gene expression by metabolic enzymes and metabolites. Nat Rev Mol Cell Biol. 2018; 19(9): 563-578, doi: 10.1038/s41580-0180029-7, indexed in Pubmed: 29930302.

16. Vernimmen D, Bickmore WA. The Hierarchy of Transcriptional Activation: From Enhancer to Promoter. Trends Genet. 2015; 31(12): 696-708, doi: 10.1016/j.tig.2015.10.004, indexed in Pubmed: 26599498.

17. LIU Y, XIONG Jw, CHEN Lg, et al. Cloning and Analysis of the Promoter Region of Rat uPA Gene. Journal of Reproduction and Contraception. 2007; 18(1): 1-10, doi: 10.1016/s10017844(07)60001-7.

18. Haile WB, Coleman JL, Benach JL. Reciprocal upregulation of urokinase plasminogen activator and its inhibitor, PAI-2, by Borrelia burgdorferi affects bacterial penetration and host-inflammatory response. Cell Microbiol. 2006; 8(8): 1349-1360, doi: 10.1111/j.1462-5822.2006.00717.x, indexed in Pubmed: 16882037.

19. Hoenigl M, Raggam RB, Wagner J, et al. Diagnostic accuracy of soluble urokinase plasminogen activator receptor (suPAR) for prediction of bacteremia in patients with systemic inflammatory response syndrome. Clin Biochem. 2013; 46(3): 225-229, doi: 10.1016/j.clinbiochem.2012.11.004, indexed in Pubmed: 23159293.

20. Yeh YH, Wang PH, Lin LY, et al. Significantly increased concentration of soluble urokinase-type plasminogen activator receptor in the blood of patients with pelvic inflammatory disease. Clin Chim Acta. 2013; 415: 138-144, doi: 10.1016/j.cca.2012.10.038, indexed in Pubmed: 23117033.

21. Xia Y, Yuan M, Li S, et al. Apigenin Suppresses the IL-1 $\beta$-Induced Expression of the Urokinase-Type Plasminogen Activator Receptor by Inhibiting MAPK-Mediated AP-1 and NF- $\kappa$ B Signaling in Human Bladder Cancer T24 Cells. J Agric Food Chem. 2018; 66(29): 7663-7673, doi: 10.1021/acs.jafc.8b02351, indexed in Pubmed: 29945448.

22. Firmal P, Shah VK, Chattopadhyay S. Insight Into TLR4-Mediated Immunomodulation in Normal Pregnancy and Related Disorders. Front Immunol. 2020; 11: 807, doi: 10.3389/fimmu.2020.00807, indexed in Pubmed: 32508811.

23. Clifton RJ, O'Donnell L, Robertson DM. Pachytene spermatocytes in co-culture inhibit rat Sertoli cell synthesis of inhibin beta B-subunit and inhibin B but not the inhibin alpha-subunit. J Endocrinol. 2002; 172(3): 565-574, doi: 10.1677/joe.0.1720565, indexed in Pubmed: 11874705.

24. Winnall WR, Muir JA, Hedger MP. Differential responses of epithelial Sertoli cells of the rat testis to Toll-like receptor 2 and 4 ligands: implications for studies of testicular inflammation using bacterial lipopolysaccharides. Innate Immun. 2011; 17(2): 123-136, doi: $10.1177 / 1753425909354764$, indexed in Pubmed: 20023008.

25. Moquet-Torcy G, Tolza C, Piechaczyk M, et al. Transcriptional complexity and roles of Fra-1/AP-1 at the uPA/Plau locus in aggressive breast cancer. Nucleic Acids Res. 2014; 42(17): 1101111024, doi: 10.1093/nar/gku814, indexed in Pubmed: 25200076.

26. Lu KH, Yang HW, Su CW, et al. Phyllanthus urinaria suppresses human osteosarcoma cell invasion and migration by transcriptionally inhibiting u-PA via ERK and Akt signaling pathways. Food Chem Toxicol. 2013; 52: 193-199, doi: 10.1016/j. fct.2012.11.019, indexed in Pubmed: 23201449.

27. Alcaraz-Pérez F, Mulero V, Cayuela ML. Application of the dual-luciferase reporter assay to the analysis of promoter activity in Zebrafish embryos. BMC Biotechnol. 2008; 8: 81, doi: 10.1186/1472-6750-8-81, indexed in Pubmed: 18954456.

28. Lie PPY, Cheng CY, Mruk DD. Signalling pathways regulating the blood-testis barrier. Int J Biochem Cell Biol. 2013; 45(3): 621-625, doi: 10.1016/j.biocel.2012.12.009, indexed in Pubmed: 23262290

29. Zhao S, Zhu W, Xue S, et al. Testicular defense systems: immune privilege and innate immunity. Cell Mol Immunol. 2014; 11(5): 428-437, doi: 10.1038/cmi.2014.38, indexed in Pubmed: 24954222.

30. Li N, Wang T, Han D. Structural, cellular and molecular aspects of immune privilege in the testis. Front Immunol. 2012; 3: 152, doi: 10.3389/fimmu.2012.00152, indexed in Pubmed: 22701457.

31. Slomiany BL, Slomiany A. Role of LPS-elicited signaling in triggering gastric mucosal inflammatory responses to $\mathrm{H}$. pylori: modulatory effect of ghrelin. Inflammopharmacology. 2017; 25(4): 415-429, doi: 10.1007/s10787-017-0360-1, indexed in Pubmed: 28516374.

32. Michailidis G, Anastasiadou M, Guibert E, et al. Activation of innate immune system in response to lipopolysaccharide in chicken Sertoli cells. Reproduction. 2014; 148(3): 259-270, doi: 10.1530/REP-14-0064, indexed in Pubmed: 24920664.

33. Yeagley D, Lang CH. Endotoxin-Induced IL-6 Promoter Activation in Skeletal Muscle Requires an NF- $\kappa$ B Site. Int J Interferon Cytokine Mediat Res. 2010; 2010(2): 9-21, doi: 10.2147/ IJICMR.S6690, indexed in Pubmed: 23874122.

34. Casals-Casas C, Alvarez E, Serra M, et al. CREB and AP-1 activation regulates MKP-1 induction by LPS or M-CSF and their kinetics correlate with macrophage activation versus proliferation. Eur J Immunol. 2009; 39(7): 1902-1913, doi: 10.1002/ eji.200839037, indexed in Pubmed: 19585511.

35. Rocha DM, Caldas AP, Oliveira LL, et al. Saturated fatty acids trigger TLR4-mediated inflammatory response. Atherosclerosis. 2016; 244: 211-215, doi: 10.1016/j.atherosclerosis.2015.11.015, indexed in Pubmed: 26687466.

36. Kawai T, Takeuchi O, Fujita T, et al. Lipopolysaccharide stimulates the MyD88-independent pathway and results in activation of IFN-regulatory factor 3 and the expression of a subset of lipopolysaccharide-inducible genes. J Immunol. 2001; 167(10): 5887-5894, doi: 10.4049/jimmunol.167.10.5887, indexed in Pubmed: 11698465.

37. Zhang H, Yin Y, Wang G, et al. Interleukin-6 disrupts blood-testis barrier through inhibiting protein degradation or activating phosphorylated ERK in Sertoli cells. Sci Rep. 2014; 4: 4260, doi: 10.1038/srep04260, indexed in Pubmed: 24584780.

38. Lei T, Moos S, Klug J, et al. Galectin- 1 enhances TNF $\alpha$-induced inflammatory responses in Sertoli cells through activation of MAPK signalling. Sci Rep. 2018; 8(1): 3741, doi: 10.1038/s41598018-22135-w, indexed in Pubmed: 29487346.

39. Iliev DB, Sobhkhez M, Fremmerlid K, et al. MyD88 interacts with interferon regulatory factor (IRF) 3 and IRF7 in Atlantic salmon (Salmo salar): transgenic SsMyD88 modulates the IRF-induced type I interferon response and accumulates in aggresomes. J Biol Chem. 2011; 286(49): 42715-42724, doi: 10.1074/jbc.M111.293969, indexed in Pubmed: 21990356.

Submitted: 7 January, 2021

Accepted after reviews: 6 November, 2021 Available as AoP: 30 November, 2021 